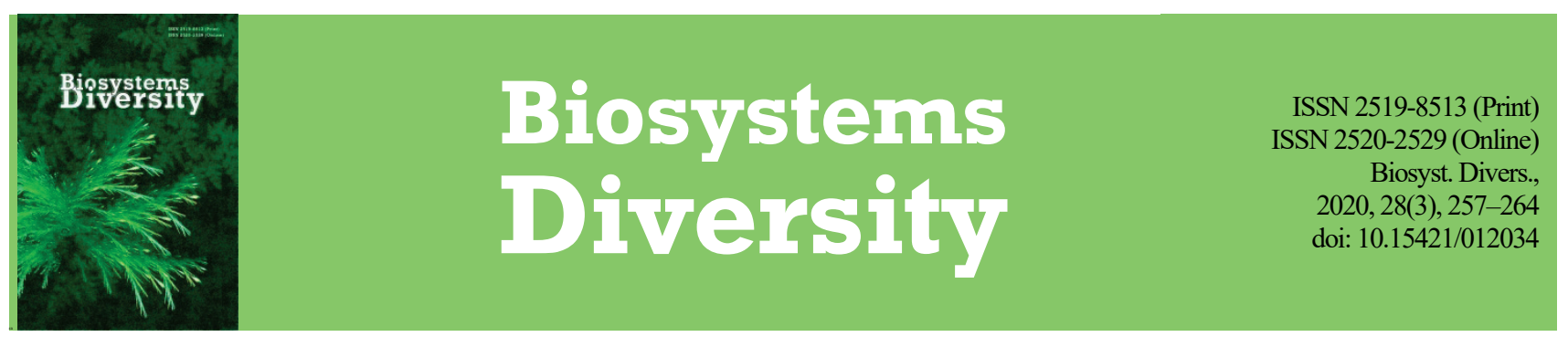

\title{
Pattern of functional diversity along the elevation gradient in the dry evergreen Afromontane forest of Hararghe Highland, Southeast Ethiopia
}

\author{
M. Teshome*,**,Z. Asfaw**, M. Mohammed* \\ *Oda Bultum University, Chiro, Ethiopia \\ **Wondo Genet College of Forestry and Natural Resources, Hawassa University, Shashemene, Ethiopia
}

Article info

Received 09.07.2020

Received in revised form 12.08 .2020

Accepted 14.08.2020

Oda Bultum University,

P. O. Box 226, Chiro,

Ethiopia.

Tel: +251-256-510-037

Wondo Genet College of Forestryand Natural Resources, Hawassa

University, P.O.Box 128

Shashemene, Ethiopia.

Tel: +251-046-211-001

E-mail:

menguteshe2012@gmail.com

\section{Introduction}

Afromontane forests are distributed across the African highlands (Linder, 2014; Abiem et al., 2020). Typically found above $1500 \mathrm{~m}$ in elevation, they extend from the Arabian Peninsula south along the East African Rift to the Drakensberg Mountains in the east. Despite this distribution, Afromontane forests have a unique fauna and flora and harbour a high proportion of endemic species (Burgess et al., 2007; Abiem et al., 2020). They have significant carbon stocks (Spracklen \& Righelato, 2014), provide watershed protection (Schröter et al., 2005) and other important ecosystem services (Conti \& Díaz, 2013). However, Afromontane forests tend to occur in areas of high human population pressure and are under intense threat from agricultural expansion, fire, and grazing (Cordeiro et al., 2007; Kebede et al., 2013). The Ethiopian highlands contribute more than half of the total land area covered by Afromontane forest, of which dry evergreen Afromontane forests occupy a large part (Friis et al., 2010). The topographic and elevation variation in Ethiopian landscapes affects the existence of different vegetation types and species diversity. A large topographic variation within small geographical areas makes the elevation gradient a unique position to study species diversity (Wana, 2009; Kebede et al., 2013). Long term monitoring of these forests is crucial for understanding how they function and for predicting their dynamics along environmental changes, vital information for sustainable management and preservation of the local and global services they provide.

Functional diversity is an important ecological attribute of a particular ecosystem (Mason et al., 2005; Conti \& Díaz, 2013). In recent decades, functional diversity has received much attention from conservationists and ecologists (Zhang et al., 2017; Thakur \& Chawla, 2019). Functional diversity is an important predictor of species in response to environmental changes and is used to describe specific functional adaptations of plants to different environmental factors (Mouchet et al., 2010; Mason \& de Bello, 2013). It is now well established that many environmental factors, inclu- ding topography (i.e. elevation, slope, and aspect), edaphic, and disturbance factors have been found to affect functional traits of plant communities (Pavoine \& Bonsall, 2011; Costa et al., 2017). Notably, elevation is one of the most frequently stated problems with the functional trait variability of plant communities. In highland ecosystems, increasing elevation is usually related to lower temperatures and higher humidity (Solefack et al., 2018). Change in this climatic variable is a stress factor for plants, which affects plant diversity by selecting biological forms capable of existing at different elevation ranges (Klimes, 2003). In addition to elevation, slope and aspect also has a significant effect on functional diversity and is important to species composition, community structure, and soil development in ecosystems (Pavoine \& Bonsall, 2011). Changes in slope aspects lead to changes in hours of sunshine, humidity, and temperature, which affect plant communities (Austrheim, 2002; Zhang et al., 2018).

Elevation found to be influencing functional diversity has been explored in several studies (Pavoine \& Bonsall, 2011; Zhang et al., 2018). More recently, literature has emerged that offers contradictory findings about functional diversity pattern along an elevation gradient (Swenson et al., 2011; Zhang et al., 2014). For instance, in the Luquillo experimental forest, Swenson et al. (2011) reported that functional diversity increased along the elevation gradient. Kluge \& Kessler (2011) suggested that environmental filtering as an important to functional diversity under stressful environmental conditions at low and high elevations, whereas interspecific competition was important to functional diversity at middle elevation. By contrast, Thakur \& Chawla (2019) observed that functional diversity decreases with increasing elevation in the high altitude vegetation of the Western Himalaya. Likewise, de Bello et al. (2013) and Gazol et al. (2017) reported a decrease in functional diversity with increasing elevation in the Alps and South Urals, respectively. Zhang et al. (2014) reported a "humped" pattern showing peak functional diversity near the middle of the gradient. However, their study suggested a possible reason for the patterns of trait variation and functional diversity variation along the eleva- 
tion gradient related to vegetation type and ecoregions. So far, little study has been done on functional diversity in relation to environmental gradient in sub-Saharan countries (Wana, 2009; Solefack et al., 2018). Most of the work on this subject has focused on the phylogenetic diversity of plant communities (Zhou et al., 2018), vegetation structure (Rutten et al., 2015), species richness pattern along elevation gradient (Tesfaye et al., 2010; Aynekulu et al., 2012; Kebede et al., 2013). This paper examines the relationship between functional diversity and environmental factors (i.e. elevation, slope and aspect) in a dry evergreen Afromontane forest. The response of functional diversity variation patterns to environmental change and the underlying causal mechanisms behind the patterns is not understood. To assist the future management and conservation of biological diversity, detecting the variation patterns of functional diversity and understanding the underlying causal mechanisms behind the patterns is essential. Therefore, the objective of this study is to describe and examine variation patterns of functional diversity of plant communities along an environmental gradient, to test the hypothesis that functional diversity decreases with increasing of elevation gradients due to environmental filtering, and to identify the key environmental variables affecting functional diversity in the studied forest.

\section{Material and methods}

The study was conducted in Dindin dry evergreen Afromontane forest in the Hararghe Highlands, Southeast Ethiopia. The geographical lo- cation of the study site lies between $40^{\circ} 10^{\prime} 40^{\prime \prime}$ to $40^{\circ} 18^{\prime} 50^{\prime \prime}$ E and $8^{\circ} 33^{\prime} 0^{\prime \prime}$ to $8^{\circ} 40^{\prime} 40^{\prime \prime} \mathrm{N}$ with elevation ranges between 2,124 and 3,069 $\mathrm{m}$ a. s. 1. and situated around $336 \mathrm{~km}$ southeast of Addis Ababa (Fig. 1). Due to the lack of long term climatic data for the study site, the climate estimator software tool, New LocClim (FAO, 2005; Grieser et al., 2006) was used to produce long term monthly rainfall and temperature data for the study site. The mean annual temperature (MAT) and mean annual precipitation (MAP) at the study site was estimated to be $25.6{ }^{\circ} \mathrm{C}$ and $804 \mathrm{~mm} / \mathrm{year}$, respectively. Precipitation at the study site has a bimodal distribution pattern with a long rainy season lasting from June to October and a short rainy season from April to May (Fig. 2). The soils of the study area developed from a wide range of parent materials, including volcanic and mixed limestone and sandstone over a Precambrian basement. Leptosols are most abundant soil types which are classified as Haplic and Lithic leptosols. Lithic leptosol covers are most extensive on high mountainous relief hills and parallel ridges and river gorges having very steep slopes (30-60\%) (Tefera et al., 1996; Elias, 2016). According to Friis et al. (2010), the vegetation type in the study area can be categorized as Tropical dry evergreen Afromontane forest, which is characterized by a dry climate. Woody species such as Afrocarpus falcatus, Maesa lanceolata, Allophylus abyssinicus and Vernonia myriantha are dominant. Along the altitudinal gradient between 2,300 and 2,900 $\mathrm{m}$ a. s. 1., a stratified systematic sampling of 54 plots separated by $200 \mathrm{~m}$ raises in elevation (2300, 2500,2700 and $2900 \mathrm{~m}$ a. s. 1.) were established at $200 \mathrm{~m}$ intervals along the four horizontal transects, the initial plot was selected randomly.

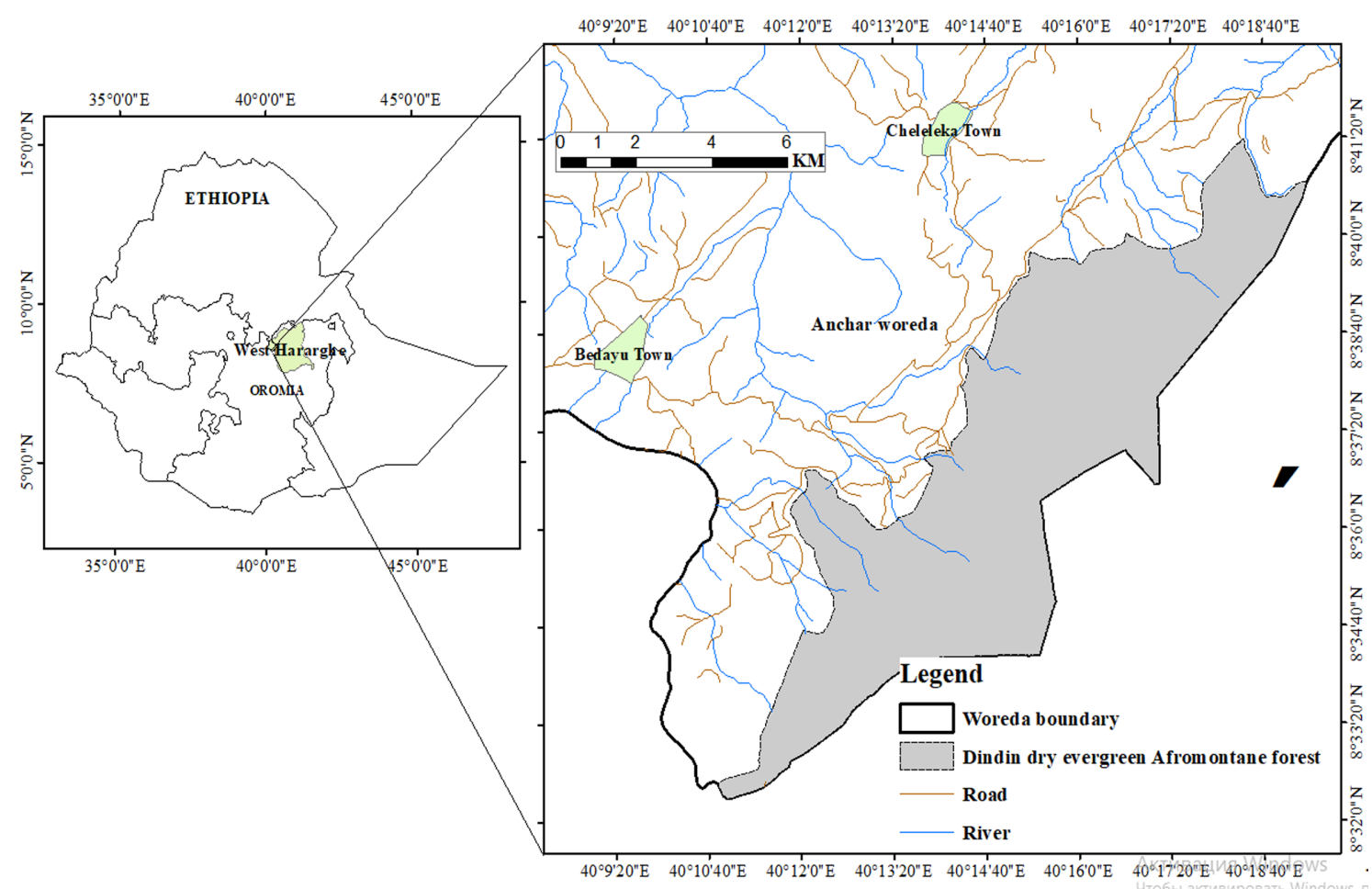

Fig. 1. Study area map

25.6C $\quad 804 \mathrm{~mm}$

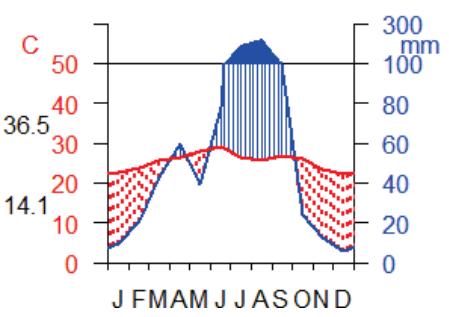

Fig. 2. Climate Diagram of study area (values generated using New_LocClim. See text)

This approach was adopted for two main reasons: (i) there is a minimum sampling bias as all woody species in the study forest are represen- ted; (ii) the effect of area (the decrease in area from bottom to top of a mountain) is minimized, as all forest areas are included. Moreover, this procedure gives a precise indication of species represented and is used to achieve better documentation of changes in species distribution patterns along an elevation gradient (Aynekulu et al., 2012; Arellano et al., 2016). The plot size of $20 \times 20 \mathrm{~m}$ was used to record trees and woody lianas, in which three $5 \times 5 \mathrm{~m}$ sub-plots were used to record shrubs. In each plot, height, diameter and individual abundance of trees and shrubs were recorded. Furthermore, all woody lianas with a $\mathrm{dbh} \geq 1 \mathrm{~cm}$ at $1.30 \mathrm{~m}$ from the rooting point were also recorded, because this could provide a detailed assessment of its diversity (Arellano et al., 2016). The habits or growth forms of each species were also recorded. For the purpose of this study, trees are one stemmed woody plants with heights $\geq 5 \mathrm{~m}$ and shrubs are represented a multi stemmed woody plants with heights $\leq 5 \mathrm{~m}$. Each species was identified in the field whenever possible, but in doubtful cases 
vouchers were collected and pressed for further identification and confirmation at the Addis Ababa University national herbarium. Environmental variables such as elevation, slope, aspect and geographical location of each plot were recorded. The elevation was measured by using a GPS garmin; whereas, the slope and aspect were measured by using a compass meter.

Two functional traits were selected to demonstrate plant species function in the community along an elevation gradient. Data on specific wood density was obtained from the Global Wood Density Database (Chave et al., 2009; Zanne et al., 2009). Wood density $\left(\mathrm{g} / \mathrm{m}^{3}\right)$ is the dry mass per unit volume of fresh wood, which is a fundamental characteristic of tree trunks (Muller-Landau, 2004) and it plays a major role in light acquisition strategies. Specific leaf area (SLA) was extracted from the TRY plant database (Kattge et al., 2011; Maire et al., 2015). SLA defined as leaf area $\left(\mathrm{cm}^{2}\right)$ per unit of leaf dry mass $(\mathrm{g})$. Average genus values for wood density and SLA was used when a particular species is missing.

There are various measurement methods for functional diversity based on species traits available in ecology. We used the following indices.

Modified functional attributes diversity (MFAD): MFAD measures the dispersion of species in the functional trait space (Schmera et al., 2009).

$$
\operatorname{MFAD}=\frac{\sum_{\mathrm{h}=1 \mathrm{k}=1}^{\mathrm{N}} \sum_{\mathrm{hk}}^{\mathrm{N}} \mathrm{d}_{\mathrm{k}}}{\mathrm{N}}
$$

where $\mathrm{d}_{\mathrm{hk}}$ is the distances between functional units $\mathrm{h}$ and $\mathrm{k}$ and $\mathrm{N}$ is the number of functional units.

Functional diversity based on dendrogram (FDp and FDc): Functional diversity based on dendrogram length is the sum of branch length of the functional dendrogram that can be calculated from a matrix of species functional traits (Petchey \& Gaston, 2006). Gower's distance and group averaging clustering were used to calculate the dendrogram (Podani \& Schmera, 2006). Gower distance is important in detecting changes in functional diversity along environmental gradients, as greater variations in trait values reflect increased niche differentiation (de Bello et al., 2012). FDp is a plot-based index which recalculates the dendrogram for each plot, FDc is a community based index (Casanoves et al., 2011).

Functional divergence (FDiv): FDiv refers to how abundance is distributed within the volume of the functional trait space (Ville'ger et al., 2008).

$$
\text { FDiv }=\frac{\sum_{i=1}^{S} w_{i}\left({d G_{i}}-\overline{d G}\right)+\overline{d G}}{\sum_{i=1}^{S} w_{i}\left|\overline{\mathrm{dG}_{i}}-\overline{d G}\right|+\overline{d G}}
$$

where $d G_{i}$ is the functional distance from species i to the gravity center of species that form the vertices of the convex hull, and $\overline{d G}$ is the mean distance of the $\mathrm{S}$ species to the gravity center. is the relative abundance of species i.

Functional dispersion (FDis): FDis is the weighted average distance in multidimensional trait space of individual species to the weighted centroid of all species, where the weights correspond to the relative abundances of the species (Laliberte \& Legendre, 2010):

$$
\text { FDis }=\sum_{i=1}^{S} w_{i} z_{i}
$$

where $w_{i}$ is the abundance of species ' $\mathrm{i}$ ' and $z_{i}$ is the distance of species 'i' to the weighted centroid c.

Functional richness (FRic): It refers to the amount of trait space filled with species in the community (Mason et al., 2005). FRic was computed as given below:

$$
\text { Fric }=\frac{\text { Fci }}{\mathrm{Rc}}
$$

where Fric - the functional richness of functional character in community i, Fci - the niche space filled by the species within the community, Rcthe absolute range of the character.

Functional evenness (FEve): Functional evenness measures the regularity of spacing between species in the trait space volume and also the evenness in the distribution of the species abundance. FEve calculated as (Pla et al., 2012):

$$
\mathrm{FEve}=\frac{\sum_{\mathrm{b}=1}^{\mathrm{S}-1} \min \left(\mathrm{PWE}_{\mathrm{b}}, \frac{1}{\mathrm{~S}-1}\right)-\frac{1}{\mathrm{~S}-1}}{1-\frac{1}{\mathrm{~S}-1}}
$$

where $\mathrm{PEWb}$ is the partial weighted evenness, $\mathrm{S}$ is species richness.
Community weight mean (CWM) of traits: Plot CWM of functional traits were calculated as the mean trait value of each genus weighted by the relative abundance of the genus in a given plot (Cavanaugh et al., 2014).

$$
\mathrm{CWM}\left(\text { trait }_{\mathrm{x}}\right)=\sum \mathrm{p}_{\mathrm{i}} \mathrm{x}_{\mathrm{i}}
$$

where CWM (traitx) is the CWM for X trait, pi is the relative cover of species $\mathrm{i}$ in the community and $\mathrm{xi}$ is the trait value for the species $\mathrm{i}$.

Taxonomic diversity: Three taxonomic diversity indices, species richness (S), species heterogeneity (Shannon-Wiener index H'), and one for species evenness (Pielou index E), were used to calculate species diversity values (Magurran, 2004).

Spearman correlations were used to analyze relationships of functional diversity, environmental variables, and species diversity. Polynomial regressions were used to test the variation patterns of functional diversity along the elevation gradient. The functional diversity indices were computed by the FDiversity software (Casanoves et al., 2011). Multi-trait functional diversity indices were computed after standardization of trait values, while a single functional trait index was calculated without standardization. Standardization was performed because studied traits differ in several orders of magnitude and scale of measurement (Pla et al., 2012). Furthermore, to determine the effect of elevation, aspect and slope (fixed effects) on different functional diversity measures, a mixed effects model (Bates et al., 2015) with 'Type III analysis of variance with Satterthwaite's method was used. To run the mixed effects model package 'Ime4' (Bates et al., 2015) was used and variables were selected by 'backward selection' using 'cAIC4'package (Saefken et al., 2018). The significant effect of fixed factors was determined using "ImerTest" package (Kuznetsova et al., 2017) in R. All the functional diversity indices (response variables) were log-transformed prior to using in the mixed effects models to achieve normality assumption.

\section{Results}

The functional diversity computed by the nine indices showed significant changes in the communities of the Dindin dry evergreen Afromontane forest. Modified functional attribute diversity (MFAD) varied between 0.152 and 3.683, Functional diversity plot based dendrogram index (FDp) between 0.609 and 6.111 , Functional diversity community based dendrogram index (FDc) between 0.738 and 6.553, Functional richness (FRic) between 0.898 and 13.074, Functional evenness (FEve) between 0.249 and 0.804, Functional divergence (FDiv) between 0.535 and 0.892 , Functional dispersion (FDis) between 0.161 and 1.233 , and 1.936 , community weight mean of wood density (CWM.WD) between 0.522 and 0.665 and community weight mean of specific leaf area (CWM.SLA) between 34.789 and 123.875. The effect of elevation gradient on most of the functional diversity indices was significant (Table 1). The functional diversity indices of woody species showed different elevation patterns, including decreases, increases, and increases then decreases. Out of the nine functional diversity indices, MFAD, FDp, FDc, FRic, FDis, and CWM.SLA provided a significant decreasing pattern (Fig. 3), whereas CWM.WD showed a slight increasing pattern with increasing elevation. The relationships between functional diversity and elevation were nonlinear (Fig. 3). In addition to elevation, other environmental variables such as slope and aspect were also a significant effect on spatial patterns of functional diversity (Table 1). There was a significant effect of elevation, slope and aspect on FDp and CWM.WD. The effect of elevation and slope was significant on MFAD and FDc, whereas slope and aspect were significantly affecting FDiv. The effect of elevation on FRic, FEve and CWM_SLA was significant. In the case of FDis, CWM.SLA and FEve significant effects of aspect were found (Table 1). However, the effect of elevation on FDiv, FDis and FEve was not significant.

A functional diversity and CWM trait was significantly correlated with species richness, Shannon Weiner diversity, and evenness in communities of the studied forest. Seven out of nine functional diversity indices were positively correlated with species richness; two out of nine negatively correlated to species richness (Table 2). Six out of nine functional diversity indices revealed similar patterns, because they are correlated with species richness (Table 2 and Fig. 4). The relationships between functional diversity indices and species richness were non linear (Fig. 4). 


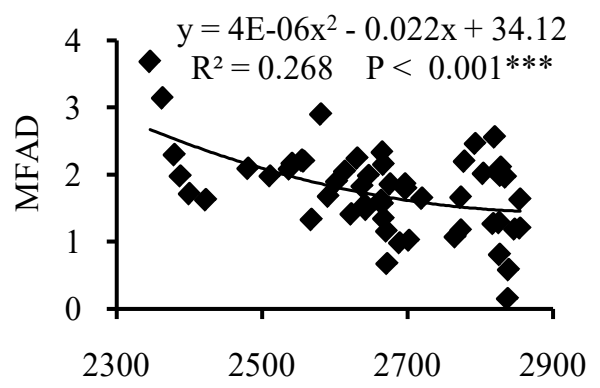

Elevation $(\mathrm{m})$

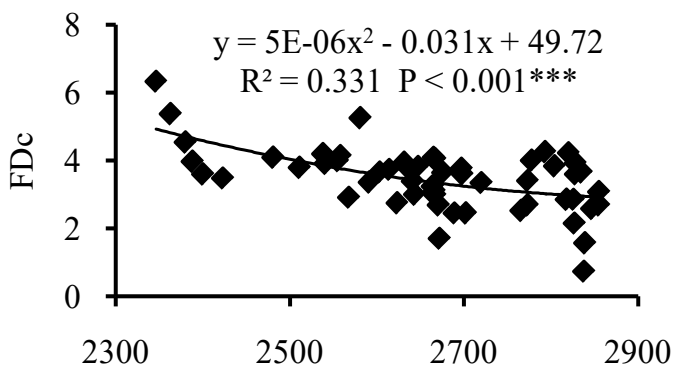

Elevation $(\mathrm{m})$
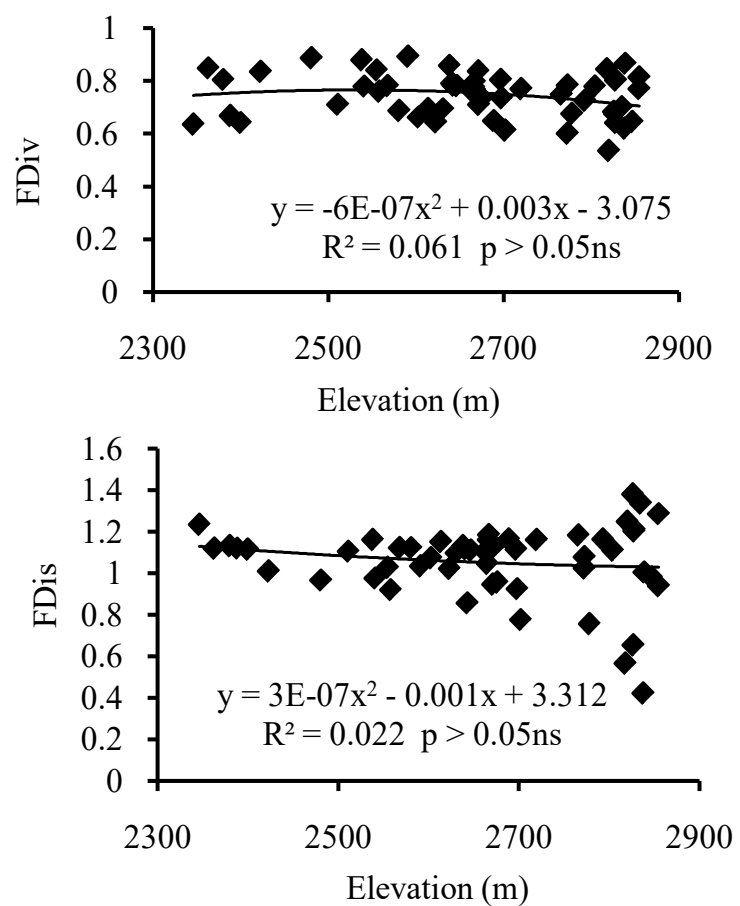
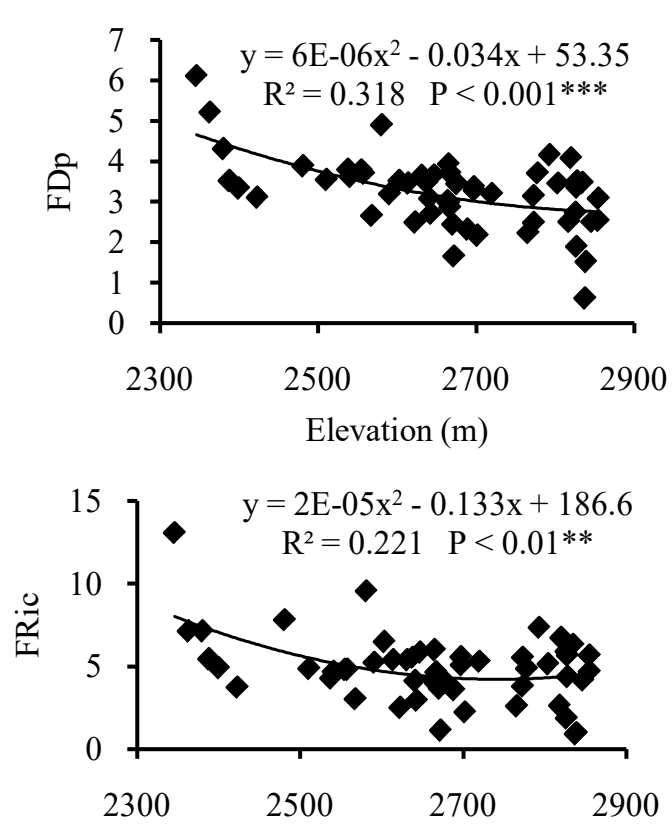

Elevation (m)
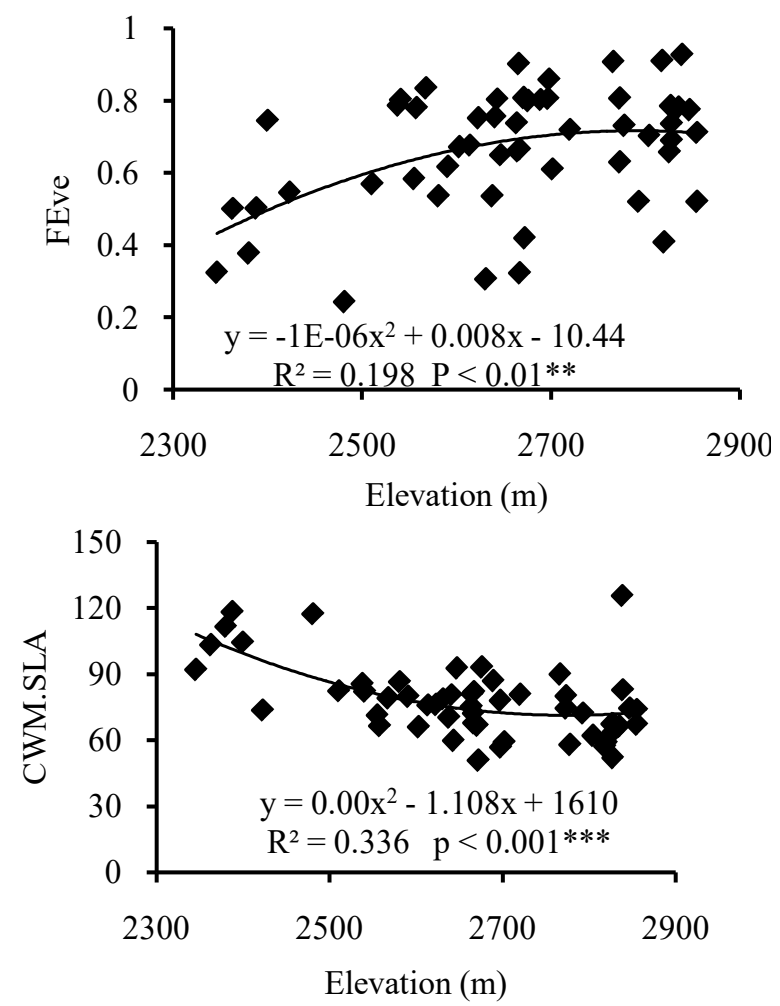

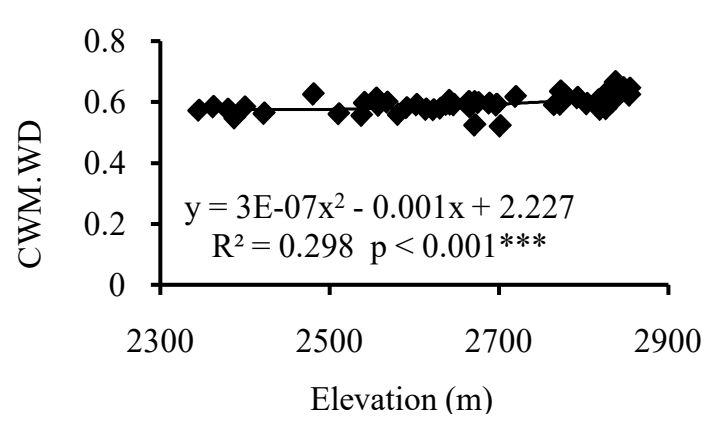

Fig. 3. Change in functional diversity along an elevation gradient in the Dindin dry evergreen Afromontane forest: MFAD - modified functional attribute diversity, FDp - plot-based functional diversity, FDc - community based functional diversity, FDiv - functional divergence, FRic - functional richness, FEve - functional evenness, FDis - functional dispersion, CWM.WD - community weight mean of woody density $\left(\mathrm{g} / \mathrm{m}^{3}\right)$, CWM.SLA - community weight mean of specific leaf area $\left(\mathrm{cm}^{2} / \mathrm{g}\right) ; * * *, * * *$ - significant effects, $\mathrm{ns}-$ not significant effects 

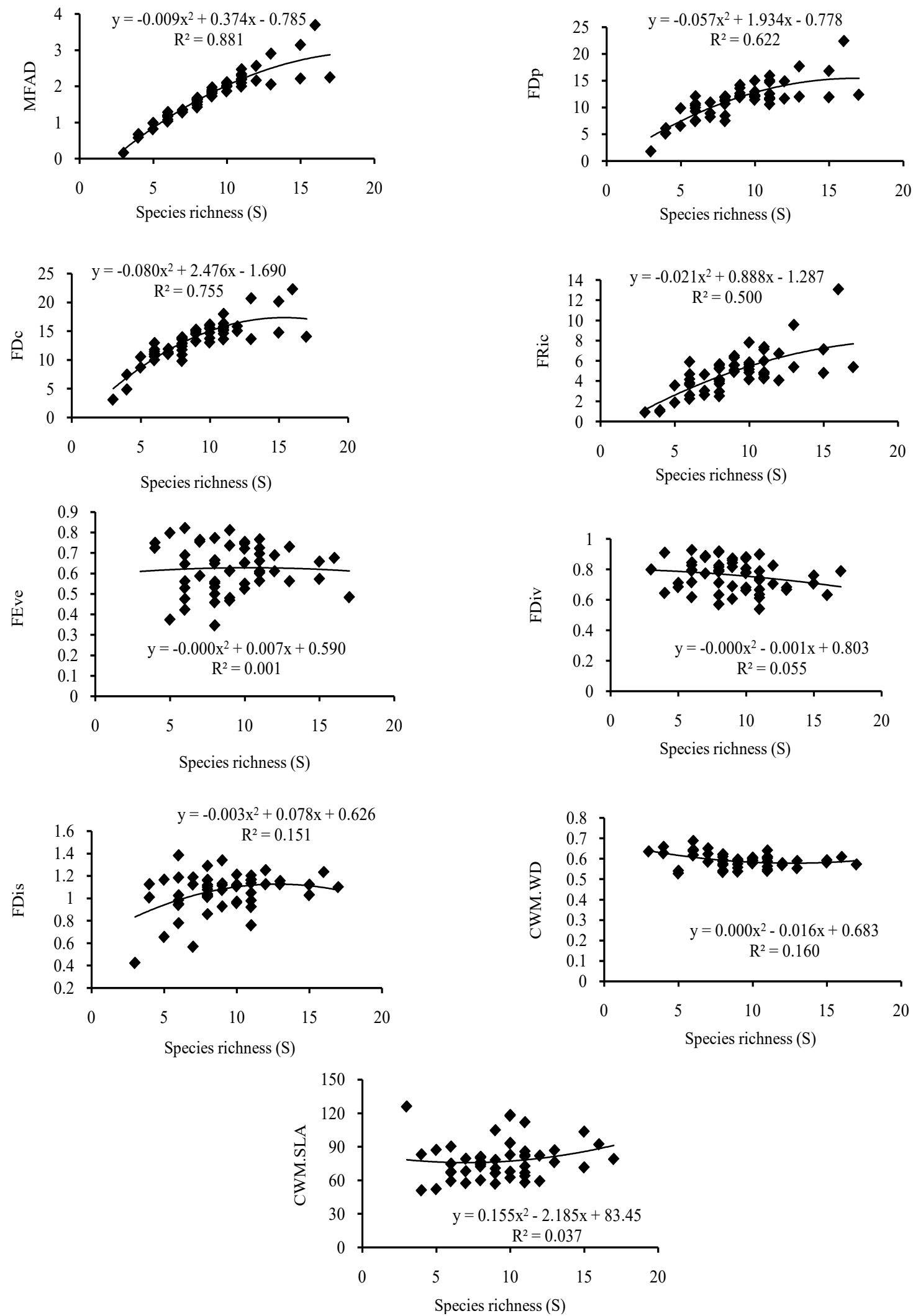

Fig. 4. Relationships between functional diversity and species richness: MFAD - modified functional attribute diversity,

FDp - plot-based functional diversity, FDc - community based functional diversity, FDiv - functional divergence,

FRic - functional richness, FEve - functional evenness, FDis - functional dispersion, CWM.WD - community weight mean of woody density $\left(\mathrm{g} / \mathrm{m}^{3}\right)$, CWM.SLA - community weight mean of specific leaf area $\left(\mathrm{cm}^{2} / \mathrm{g}\right)$

\section{Discussion}

The results revealed that functional diversity varied significantly in plant communities of the Dindin dry evergreen Afromontane forest, which indicated that functional diversity was a suitable indicator for quan- tifying relationships of function, and the environment in communities (Mason et al., 2005). In this study, the nine functional diversity indices used were all successful in demonstrating the quantity and variation pattern of functional diversity in communities, but their effectiveness was different (Mason et al., 2005; Zhang et al., 2014). In line with the hypothe- 
sis, there were a significant decrease in functional diversity indices, particularly MFAD, FDp, FRic, and FDc showed a clear decrease with increasing elevation; which is attributed to increasing environmental filtering at high elevations (Kluge \& Kessler, 2011; Gazol et al., 2017; Thakur \& Chawla, 2019). These patterns suggest that functionally more similar species should coexist (i.e. convergence in plant functional trait) at higher elevations. This could be due to increased climatic severity, less competition for resources and increased positive interactions between species at high elevations.

\section{Table 1}

Summary of statistics from mixed effects model representing effect of elevation, aspect and slope gradient on functional diversity components with 'type III' analysis of variance and Satterthwaite's method

\begin{tabular}{cccccc}
\hline $\begin{array}{c}\text { Functional } \\
\text { diversity component }\end{array}$ & Effect & Estimate & d.f. & SE & P value \\
\hline MFAD & elevation & -0.0011 & 43.846 & 0.0004 & $<0.01^{* *}$ \\
& slope & -0.0064 & 40.740 & 0.0027 & $<0.05^{*}$ \\
FDp & elevation & -0.0009 & 43.673 & 0.0003 & $<0.01^{* *}$ \\
& slope & -0.0039 & 41.345 & 0.0019 & $<0.05^{*}$ \\
& aspect & -0.4039 & 22.864 & 0.2281 & $>0.05^{\mathrm{ns}}$ \\
FDc & elevation & -0.0009 & 43.640 & 0.0003 & $<0.001^{* * *}$ \\
& slope & -0.0040 & 42.017 & 0.0018 & $<0.05^{*}$ \\
FRic & elevation & -0.0058 & 47.885 & 8.1620 & $<0.01^{* *}$ \\
FDis & aspect & -0.3584 & 18.799 & 0.1543 & $<0.05^{*}$ \\
FDiv & slope & -0.0015 & 23.980 & 0.0008 & $>0.05^{\mathrm{ns}}$ \\
& aspect & -0.2558 & 43.980 & 0.1466 & $>0.05^{\mathrm{ns}}$ \\
FEve & aspect & -0.1824 & 43.381 & 0.1078 & $>0.05^{\mathrm{ns}}$ \\
CWM.WD & elevation & 0.0001 & 43.120 & 0.0000 & $<0.001^{* * *}$ \\
& slope & -0.0005 & 42.450 & 0.0003 & $>0.05^{\mathrm{ns}}$ \\
& aspect & -0.1415 & 43.080 & 0.0646 & $<0.05^{*}$ \\
CWM.SLA & elevation & -0.0009 & 25.068 & 0.0002 & $<0.001^{* * *}$ \\
& aspect & 0.2680 & 43.886 & 0.1402 & $>0.05^{\mathrm{ns}}$ \\
\hline
\end{tabular}

Notes: d.f. - degrees of freedom, SE - standard error; $* * *, * *, *$ - significant effects, ${ }^{n s}$ - not significant effects; MFAD - modified functional attribute diversity, FDp plot-based functional diversity, FDc - community based functional diversity, FDiv functional divergence, FRic - functional richness, FEve - functional evenness, FDis - functional dispersion, CWM.WD - community weight mean of woody density $\left(\mathrm{g} / \mathrm{m}^{3}\right)$, CWM.SLA - community weight mean of specific leaf area $\left(\mathrm{cm}^{2} / \mathrm{g}\right)$

\section{Table 2}

Spearman correlation coefficients between the nine functional diversity indices and species richness, diversity and evenness in plant communities

\begin{tabular}{lccc}
\hline $\begin{array}{c}\text { Functional } \\
\text { diversity component }\end{array}$ & $\begin{array}{c}\text { Species } \\
\text { richness (S) }\end{array}$ & $\begin{array}{c}\text { Shannon Weiner } \\
\text { diversity }\left(\mathrm{H}^{\prime}\right)\end{array}$ & $\begin{array}{c}\text { Evenness } \\
\text { index }(\mathrm{E})\end{array}$ \\
\hline MFAD & $0.97^{* * *}$ & $0.87^{* * *}$ & $0.35^{* *}$ \\
FDp & $0.94^{* * *}$ & $0.84^{* * *}$ & $0.34^{*}$ \\
FDc & $0.94^{* * *}$ & $0.85^{* * *}$ & $0.34^{*}$ \\
FRic & $0.66^{* * *}$ & $0.69^{* * *}$ & $0.41^{* *}$ \\
FEve & $0.06^{\mathrm{ns}}$ & $0.14^{\mathrm{ns}}$ & $0.30^{* *}$ \\
FDiv & $-0.28^{*}$ & $-0.26^{\mathrm{ns}}$ & $-0.10^{\mathrm{ns}}$ \\
FDis & $0.24^{\mathrm{ns}}$ & $0.42^{* *}$ & $0.50^{* * *}$ \\
CWM.WD & $-0.36^{* *}$ & $-0.37^{*}$ & $-0.18^{\mathrm{ns}}$ \\
CWM.SLA & $0.20^{\mathrm{ns}}$ & $0.34^{*}$ & $0.34^{*}$ \\
\hline
\end{tabular}

Notes: $* * *-\mathrm{P}<0.001,{ }^{* *}-\mathrm{P}<0.01,{ }^{*}-\mathrm{P}<0.05,{ }^{\mathrm{n}}-$ not significant; MFAD modified functional attribute diversity, FDp - plot-based functional diversity, FDc community based functional diversity, FDiv - functional divergence, FRic - functional richness, FEve - functional evenness, FDis - functional dispersion, CWM.WD community weight mean of woody density $\left(\mathrm{g} / \mathrm{m}^{3}\right)$, CWM.SLA - community weight mean of specific leaf area $\left(\mathrm{cm}^{2} / \mathrm{g}\right)$.

Spasojevic et al. (2014) confirmed that species at high elevations are functionally more similar to each other and have lower functional diversity. In agreement with this study, Thakur \& Chawla (2019) observed that FRic decreased with increasing elevation in the high altitude vegetation of the western Himalayas. Similarly, de Bello et al. (2013) and Gazol et al. (2017) reported a decrease in FRic with increasing elevation in the Alps and South Urals. In this study, functional dispersion (FDis) and functional divergence (FDiv) of woody species showed no significant decrease with increasing elevation; the underlying processes driving the patterns might be explained by the gradients of climate and habitat variables as well as biotic interactions such as competition (Chun \& Lee, 2017). With high elevation vegetation, the decreasing pattern with increasing elevation of
FRic indicates less resource use at higher elevations, whereas, those of FDiv, and FDis indicate less niche differentiation, and niche complementary at higher elevations (Kraft et al., 2008; Thakur \& Chawla, 2019). Functional eveness showed a significant humped pattern. Similarly, Zhang et al. (2014) reported that functional eveness initially increases with increasing elevation and then decreases.

CWM.SLA showed a significant decrease with increasing elevation and may be attributed to the filtering effect of decreased temperature. Similar trends in CWM.SLA have been previously reported for Mount Hamaliya (Thakur \& Chawla, 2019) and Mount Kilimanjaro (Costa et al., 2017). However, CWM.WD revealed a significant increase with increasing elevation. The dominant functional traits (high wood density and low specific leaf area) in the stressful areas are indicative of a stress tolerant life history strategy (Swenson \& Enquist, 2007). The variation in patterns of traits and functional diversity along the elevation gradient might be attributed to vegetation type and ecoregions (Thakur \& Chawla, 2019).

Other environmental variables slope and aspect also had significant effects on functional diversity. Slope and aspect are independent of elevation and are important to species composition, community structure, and soil development in ecosystems (Pavoine \& Bonsall 2011). Zhang et al. (2018) noted that slope gradient is an essential factor affecting plant communities in alpine meadows, due to the physical and chemical characteristics of the soil and water content. Elliott \& Kipfmueller (2010) suggest that seedling recruitment is strongly influenced by slope, aspect and is a potential complicating factor of future ecological dynamics on south facing slopes, particularly within the context of climate change.

There was significant correlation between functional diversity indices and species richness, Shannon, and Evenness in the studied forest. This suggests that functional diversity and species richness are interrelated with each other. A positive relationship of species richness and functional diversity indicates that each species has a relatively unique set of traits $(\mathrm{Bu}$ et al., 2014) and functional complementarity usually appears in some respects among different species. The positive relationship between species diversity and functional diversity in this study is consistent with previous studies (Caddotte et al., 2011; Zhang et al., 2014, 2018). These results build on existing evidence of the relationship between species diversity and functional diversity influenced by the sensitivity of the functional diversity metric to functional variation between species. Furthermore, the non linear relationships between functional diversity and species richness confirmed that they cannot be replaced with each other (Zhang et al., 2014). There are some changes in functional traits which may go beyond the change that can be explained only through taxonomic diversity variation (Ricotta \& Moretti, 2008). The variation in species abundance and distribution can mainly explained through species diversity, however functional diversity can explain variations of species morphology, physiology, reproduction, ecology and phenology (Papanikolaou et al., 2011).

\section{Conclusions}

Most of the functional diversity indices showed a decreasing pattern with increasing elevation in Dindin dry evergreen Afromontane forest, which indicates that elevation is the most important environmental filter which influences the species distribution, community composition and structure in the communities. Further, slope and aspect have a significant effect on the plant distribution and functioning of high elevation plant communities. Knowledge of the role of environmental filtering in changing community composition and functional diversity in the dry evergreen Afromontane forest is very important for understanding of diversity changes and ecosystem processes. Further studies should be conducted to monitor and predict the effects of climate change on the fragile dry evergreen Afromontane ecosystems which are mediated through soil moisture content.

We appreciate the collaboration of Oromia Forest and Wildlife enterprise, Dindin district workers for their help during the fieldwork in the Dindin natural forest. Besides, we thank Mr. Mekonnen Beyene (Oda Bultum University, Ethiopia) for his collaboration collecting vegetation samples from all the plots of this study. In addition, we thank Dr Motuma Tolera (Hawassa University, Ethiopia) and Dr Dong Gill Kim (Hawassa University, Ethiopia) for their valuable suggestions for this paper. 


\section{References}

Abiem, I., Arellano, G., Kenfack, D., \& Chapman, H. (2020). Afromontane forest diversity and the role of grassland-forest transition in tree species distribution. Diversity, 12,30 .

Arellano, G., Cala, V., Fuentes, A., Cayola, L., Jørgensen, P. M., \& Macía, M. J. (2016). A standard protocol for woody plant inventories and soil characterisation using temporary 0.1 -ha plots in tropical forests. Journal of Tropical Forest Science, 28(4), 508-516.

Austrheim, G. (2002). Plant diversity patterns in semi-natural grasslands along an elevational gradient in southern Norway. Plant Ecology, 161(2), 193-205.

Aynekulu, E., Gebrehiwot, K., Boehmer, H. J., Aerts, R., Moonen, P., Vagen, T. G., Denich, M., \& Mekuria, W. (2012). Altitudinal variation and conservation priorities of vegetation along the Great Rift Valley escarpment, northern Ethiopia. Biodiversity Conservation, 21, 2691-2707.

Bates, D, Mächler, M, Bolker, B., \& Walker, S. (2015). Fitting linear mixed-effects models using lme4. Journal of Statistical Software, 67(1), 1-48.

Bu, W., Zang, R., \& Ding, Y. (2014). Functional diversity increases with species diversity along successional gradient in a secondary tropical lowland rainforest. Tropical Ecology, 55(3), 393-401.

Burgess, N. D., Balmford, A., Cordeiro, N. J., Fjeldsa, J., Küper, W., Rahbek, C., Sanderson, E. W., Scharlemann, J. P., Sommer, J. H., \& Williams, P. H. (2007). Correlations among species distributions, human density and human infrastructure across the high biodiversity tropical mountains of Africa. Jornal of Biological Conservation, 134, 164-177.

Caddotte, M. W., Carscadden, K., \& Mirotchnick, N. (2011). Beyond species: Functional diversity and the maintenance of ecological processes and services: Review. Journal of Applied Ecology, 48, 1079-1087.

Casanoves, F., Pla, L., Di Rienzo, J. A., \& Díaz, S. (2011). FDiversity: A software package for the integrated analysis of functional diversity. Methods in Ecology and Evolution, 2, 233-237.

Cavanaugh, K. C., Gosnell, J. S., Davis, S. L., Ahumada, J., Boundja, P., Clark, D. B., \& Andelman, S. (2014). Carbon storage in tropical forests correlates with taxonomic diversity and functional dominance on a global scale. Global Ecology and Biogeography, 23, 563-573.

Chave, J., Coomes, D., Jansen, S., Lewis, S. L., Swenson, N. G., \& Zanne, A. E. (2009). Towards a worldwide wood economics spectrum. Ecology Letters, 12, 351-366.

Chun, J. H., \& Lee, C. B. (2017). Disentangling the local-scale drivers of taxonomic, phylogenetic and functional diversity in woody plant assemblages along elevational gradients in South Korea. PLoS One, 12(10), e0185763.

Conti, G., \& Díaz, S. (2013). Plant functional diversity and carbon storage-an empirical test in semi-arid forest ecosystems. Journal of Ecology, 101, 18-28.

Cordeiro, N. J., Burgess, N. D., Dovie, D. B., Kaplin, B. A., Plumptre, A. J., \& Marrs, R. (2007). Conservation in areas of high population density in sub-Saharan Africa. Biological Conservation, 134(2), 155-163.

Costa, S. D., Gerschlauer, F., \& Pabst, H.,Kuhnel, A., Huwe, B., Kiese, R. Kuzyakov, Y., \& Kleyer, M. (2017). Community-weighted means and functional dispersion of plant functional traits along environmental gradients on Mount Kilimanjaro. Journal of Vegitation Science, 28, 684-695.

de Bello, F., Carmona, C. P., Mason, N. W. H., Sebastia, M. T., \& Leps, J. (2012) Which trait dissimilarity for functional diversity: Trait means or trait overlap? Journal of Vegetation Science, 24(5), 807-819.

de Bello, F., Lavorel, S., Lavergne, S., Albert, C. H., Boulangeat, I., Mazel, F., \& Thuiller, W. (2013). Hierarchical effects of environmental filters on the functional structure of plant communities: A case study in the French Alps. Ecography, 36, 393-402.

Elias, E. (2016). Soils of the Ethiopian Highlands: Geomormology and proporties. CASCAPE Project, ALTERA, Wageningen University and Research Centre (Wageningen UR), The Netherlands.

Elliott, G. P., \& Kipfimueller, K. F. (2010). Multi-scale influences of slope aspect and spatial pattern on ecotonal dynamics at upper treeline in the Southern Rocky Mountains, U.S.A. Arctic, Antarctic, and Alpine Research, 42(1), 45-56.

FAO (2005). New LocClim: local climate estimator (version 1.10). Environment and natural resources, working paper number 20 (CD-ROM). FAO, Rome.

Friis, I. B., Demissew, S., \& Breugel, P. (2010). Atlas of the potential vegetation of Ethiopia. Det Kongelige Danske Videnskabernes Selskab.

Gazol, A., Moiseev, P., \& Camarero, J. J. (2017). Changes in plant taxonomic and functional diversity patterns following treeline advances in the South Urals. Plant Ecology and Diversity, 10, 283-292.

Grieser, J., Gommes, R., \& Bernardi, M. (2006). New LocClim-the local climate estimator of FAO. Geophysical Research Abstracts, 8, 2

Kattge, J., Diaz, S., \& Lavore, S. et al. (2011). TRY - a global database of plant traits. Global Change Biology, 17, 2905-2935.

Kebede, M., Yirdaw, E., Luukkanen, O., \& Lemenih, M. (2013). Plant community analysis and effect of environmental factors on the diversity of woody species in the moist Afromontane forest of Wondo Genet, South Central Ethiopia. Biodiversity Research and Conservation, 29, 63-80.

Klimeš, L. (2003). Life-forms and clonality of vascular plants along an altitudinal gradient in E Ladakh (NW Himalayas). Basic and Applied Ecology, 4, 317-328.

Kluge, J., \& Kessler, M. (2011). Phylogenetic diversity, trait diversity and niches: Species assembly of ferns along a tropical elevational gradient. Journal of Biogeography, 38, $394-405$.

Kraft, N. J. B., Valencia, R., \& Ackerly, D. D. (2008). Functional traits and niche-based tree community assembly in an Amazonian forest. Science, 322, 580-582.

Kuznetsova, A., Brockhoff, P. B., \& Christensen, R. H. B. (2017). lmerTest Package: Tests in linear mixed effects models. Joumal of Statistical Software, 82(13), 1-26.

Linder, H. P. (2014). The evolution of African plant diversity. Frontier Ecology and Evolution, 2, 38 .

Magurran, A. E. (2004). Measuring biological diversity. Blackwell Science Ltd. Australia.

Maire, V., Wright, I. J., Prentice, I. C., Batjes, N. H., Bhaskar, R., van Bodegom, P. M., Cornwell, W. K., Ellsworth, D., Niinemets, U., Ordonez, A., Reich, P. B., \& Santiago, L. S. (2015). Global effects of soil and climate on leaf photosynthetic traits and rates. Global Ecology and Biogeography, 24(6), 706-717.

Mason, N. W. H., Mouillot, D., Lee, W. G., Wilson, J. B., \& Setälä, H. (2005). Functional richness, functional evenness and functional divergence: The primary components of functional diversity. Oikos, 111(1), 112-118.

Mason, N. W., \& de Bello, F. (2013). Functional diversity: A tool for answering challenging ecological questions. Journal of Vegetation Science, 24, 777-780.

Mouchet, M. A., Villéger, S., Mason, N. W. H., \& Mouillot, D. (2010). Functional diversity measures: An overview of their redundancy and their ability to discriminate community assembly rules. Functional Ecology, 24, 867-876.

Muller-Landau, H. C. (2004). Interspecific and intersite variation in wood specific gravity of tropical trees. Biotropica, 36, 20-32.

Papanikolaou, A. D., Fyllas, N. M., Mazaris, A. D., Dimitrakopoulos, P. G., Kallimanis, A. S., \& Pantis, J. D. (2011). Grazing effects on plant functional group diversity in Mediterranean shrublands. Biodiversity Conservation, 20, 2831-2843.

Pavoine, S., \& Bonsall, M. B. (2011). Measuring biodiversity to explain community assembly: A unified approach. Biological Reviews, 86, 792-812.

Petchey, O. L., \& Gaston, K. J. (2006). Functional diversity: Back to basics and looking forward. Ecological Letter, 9, 741-758.

Pla, L., Casanoves, F., \& Rienzo, J. D. (2012). Quantifying functional biodiversity. Springer, Dordrecht, Heidelberg, London, New York

Podani, J., \& Schmera, D. (2006). On dendrogram-based measures of functional diversity. Oikos, 115, 179-185.

Ricotta, C., \& Moretti, M. (2008). Quantifying functional diversity with graph-theoretical measures: Advantages and pitfalls. Community Ecololgy, 9(1), 11-16.

Rutten, G., Ensslin, A., Hemp, A., \& Fischer, M. (2015). Vertical and horizontal vegetation structure across natural and modified habitat types at Mount Kilimanjaro. PLoS One, 10(9), e0138822.

Schmera, D., Eros, T., \& Podani, J. (2009). A measure for assessing functional diversity in ecological communities. Aquatic Ecology, 43, 157-167.

Schröter, D., Cramer, W., Leemans, R., Prentice, I. C., Araújo, M. B., Arnell, N. W., Bondeau, A., Bugmann, H., Carter, T. R., \& Gracia, C. A. (2005). Ecosystem service supply and vulnerability to global change in Europe. Science, 310, 1333-1337.

Solefack, M. C. M., Fedoung, E. F., \& Temgoua, L. F. (2018). Factors determining floristic composition and functional diversity of plant communities of Mount Oku forests, Cameroon. Journal of Asia-Pacific Biodiversity, 11, 284-293.

Spasojevic, M. J., Copeland, S., \& Suding, K. N. (2014). Using functional diversity patterns to explore metacommunity dynamics: A framework for understanding local and regional influences on community structure. Ecography, 37,939-949.

Spracklen, D., \& Righelato, R. (2014). Tropical montane forests are a larger than expected global carbon store. Biogeosciences, 11, 2741-2754.

Swenson, N. G., \& Enquist, B. J. (2007). Ecological and evolutionary determinants of a key plant functional trait: Wood wensity and its community wide variation across latitude and elevation. American Journal of Botany, 94(3), 451-459.

Swenson, N. G., Anglada-Cordero, P., \& Barone, J. A. (2011). Deterministic tropical tree community turnover: Evidence from patterns of functional beta diversity along an elevational gradient. Proceedings of the Royal Society B, 278, 877-884.

Tefera, M., Chernet, T., \& Haro, W. (1996). Explanation of the geological map of Ethiopia (1:2000,000 scale). Second edition. Ethiopian Institute of Geological Survey, Addis Ababa.

Tesfaye, G., Teketay, D., Fetene, M., \& Beck, E. (2010). Regeneration of seven indigenous tree species in a dry afromontane forest, Southern Ethiopia. Flora, 205, 135-143.

Thakur, D., \& Chawla, A. (2019). Functional diversity along elevational gradients in the high altitude vegetation of the Western Himalaya. Biodiversity and Conservation, 8-9, 1-20

Villéger, S., Mason, N. W. H., \& Mouillot, D. (2008). New multidimensional functional diversity indices for a multifaceted framework in functional ecology. Ecology, 89, 2290-2301. 
Wana, D. (2009). Plant species and functional diversity along altitudinal gradients, Southwest Ethiopian Highlands. Bayreuth.

Zanne, A. E., Lopez-Gonzalez, G., Coomes, D. A., Ilic, J., Jansen, S., Lewis, S. L., Miller, R. B., Swenson, N. G., Wiemann, M. C., \& Chave, J. (2009). Global wood density database. Dryad.

Zhang, J. T., Bai, X., \& Shao, D. (2017). Functional diversity and its attribute factors in the Yunmeng Mountain National Forest Park in Beijing, China. Cerne, 23(1), 75-84.

Zhang, J. T., Li, M., \& Nie, E. (2014). Pattern of functional diversity along an altitudinal gradient in the Baihua Mountain Reserve of Beijing, China. Brasilian Journal of Botany, 37, 37-45.
Zhang, J.-T., Zhang, B., Li, M., \& Zhu, X. (2013). Functional diversity and conservation of Phellodendron amurense communities in the Dongling Mountain of Beijing, China. Botanical Sciences, 91(4), 505-513.

Zhang, Q. P., Wang, J., Gu, H. L., Zhang, Z.-G., \& Wang, Q. (2018). Effects of continuous slope gradient on the dominance characteristics of plant functional groups and plant diversity in alpine meadows. Sustainability, 10, 4805

Zhou, Y., Chen, S., Hu, G., Mwachala, G., Yan, X., \& Wang, Q. (2018). Species richness and phylogenetic diversity of seed plants across vegetation zones of Mount Kenya, East Africa. Ecology and Evolution, 8, 8930-8939. 